\title{
A Revolution in Dentistry: Epigenetics
}

\author{
Namita Sepolia ${ }^{1}$ Deepti Garg Jindal ${ }^{1} \quad$ Sandhya Singh Kaushwaha ${ }^{1}$ Varun Jindal ${ }^{2}$ Monika Negi ${ }^{3}$
}

\author{
${ }^{1}$ Department of Oral and Maxillofacial Pathology and Microbiology, \\ Bhojia Dental College \& Hospital, Solan, Himachal Pradesh, India \\ ${ }^{2}$ Department of Conservative and Endodontics, Bhojia Dental \\ College \& Hospital, Solan, Himachal Pradesh, India \\ ${ }^{3}$ Department of Oral and Maxillofacial Pathology and Microbiology, \\ Himachal Institute of Dental Sciences, Pontasahib, Himachal \\ Pradesh, India
}

\author{
Address for correspondence Namita Sepolia, Department of Oral \\ and Maxillofacial Pathology and Microbiology, Bhojia Dental College \\ \& Hospital, Budh, Baddi, Solan 173205, Himachal Pradesh, India \\ (e-mail: namitasepolia@gmail.com).
}

\begin{abstract}
Keywords

- dentistry

- DNA methylation

- epigenetics

Epigenetics is the study of potentially heritable changes in gene expression that does not involve changes in underlying DNA sequence. Epigenetic mechanisms play a crucial role in cellular proliferation, migration, and differentiation in both normal and neoplastic development. Epigenetic changes may be inherited and can occur during embryonal development or after birth. Once the change in DNA methylation takes place, following cell division the altered pattern is transferred into daughter cells by the action DNA methyltransferase enzyme, which recognizes hemi-methylated sites and methylates newly synthesized DNA formed during replication. Recently, it has been suggested that aberrant DNA methylation of cytosine-phosphate-guanine (CpG) islands is a common event in odontogenic tumors. Expression of DNA methyltransferase $1,3 \mathrm{~A}, 3 \mathrm{~B}$ has been noted in various odontogenic tumors. Thus, this review aims to study the various epigenetic pathways that are altered in odontogenic tumors.
\end{abstract}

\section{Introduction}

In the mid-1960s, for the first time the word "epigenetics" came into existence, which was put forward by Waddington. It was derived from "epigenesis" that is a seldomly used term for the branch of biology that studies the interactions between genes and their products. ${ }^{1}$ Aristotelian theory of epigenesis states that developmental changes are unspectacular and qualitative but are linked to current and future studies of heredity. "Epi" means "upon" or "over," and the "genetics" part of epigenetics implies that genes are involved, so the term reflected the need to study events "over" or beyond the gene. ${ }^{2}$ In 1982, dictionary of biology defined it as "Pertaining to the interaction of genetic factors and the developmental processes through which the genotype is expressed in the phenotype." ${ }^{3}$

In the early 1990s, a new flavor was added to epigenetics. In 1992, Hall wrote in the first edition of Evolutionary Developmental Biology that "Epigenetics or epigenetic control is the sum of the genetic and nongenetic factors acting upon cells to selectively control the gene expression that produces increasing phenotypic complexity during development." Later on in 1996, book entitled Epigenetic Mechanisms of
Gene Regulation described it as "The study of mitotically and/or meiotically heritable changes in gene function that cannot be explained by changes in DNA sequence." ${ }^{5}$

With advancing time, the epigenetics has grown more widely not only in the field of biology, medicine but also in the field of dentistry. In 2001, Wu and Morris wrote epigenetics as: "The study of changes in gene function that are mitotically and/or meiotically heritable and that do not entail a change in DNA sequence." ${ }^{6}$ In past 20 years, developmental discoveries have modified our comprehension of epigenetics from a biological phenomenon to a functionally dissected research field. ${ }^{7}$ The field of epigenetics is metamorphosing our perception of biology, medicine, and evolution. However, epigenetics itself has undergone an evolutionary process over the past decade. ${ }^{8}$ Various predisposing factors such as smoking, diet, inflammation, stimuli, and age seem to affect gene regulation, which leads to epigenetic modification in the genome. ${ }^{9}$ Inheritance mechanisms that are controlled by genes that encode the enzymes of methylation of DNA, modification of histones, RNA regulatory apparatus, and dynamical chromosomal structures that are produced by numerous regulatory proteins both local and lengthy but received

December 6, 2018

accepted after revision

February 11, 2019

published online

April 4, 2019
DOI https://doi.org/

$10.1055 / \mathrm{s}-0039-1685128$

ISSN 2321-1482.
(C2019 Bhojia Dental College and Hospital affiliated to Himachal Pradesh University
License terms

(1) (1) $\ominus \circledast$ 
are not associated with changes in the gene sequence, scrutinized by epigenetics. ${ }^{10}$ So far only a small fraction of genes that control mechanisms of epigenetic regulation have been identified.

\section{DNA Methylation}

These are DNA chains in which the changes take place by the transfer of covalent methyl group from S-adenosyl methionine (SAM) to cytosines, which is present in cytosine-phosphate-guanine $(\mathrm{CpG}){ }^{11}$ For normal development, DNA methylation is required, and significant role is played by DNA methylation in various mechanisms such as genomic imprinting, inactivation of X-chromosome, and suppression in repetitive element transcription and transposition and diseases such as cancer. ${ }^{12-15}$

$\mathrm{CpG}$ islands and regions enriched with GC contain 5' regions of various genes that are unmethylated $\mathrm{CpG}$ dinucleotides. Inhibition of binding transcription factors to DNA occurs when methyl group attaches to DNA groove ( - Fig. 1). ${ }^{16}$

Interaction with methyl-binding proteins is allowed by the exposed methylation sites, for example methyl-1 CpG-binding domain proteins (MBDs). ${ }^{17}$ It has been reported that instability of chromosome and transposable element in human cancer are activated by the methylation changes in the DNA. ${ }^{18}$

\section{Histone Modification}

For the regulation of gene expression, a heritable mechanism is provided by the histone proteins and core components of chromatin. ${ }^{19}$ Expression of gene is regulated by the modification of histone tails, as staged by the histone code hypothesis. Gene expression regulated by these modifications are domains providing specific binding sites for the proteins. ${ }^{10}$ Gene transportation is facilitated by an open chromatin conformation as a result of acceleration of histones, allowing for the recruitment of the basic transcription factors. In contrast, gene transportation is repressed by the condensed chromatin, which is caused by histone deacetylation, which removes the acetyl groups ${ }^{9}$ (-Fig. 2).

\section{Epigenetics in Dentistry}

Various researches have been done in the branch of medicine and biology, but in dentistry it still requires more attempts. Dental anomalies are the result of complex interactions between genetic, epigenetic, and environmental factors during the long process of dental development.9,11,13-23 It is believed that various environmental factors that affect epigenetics include diet, drugs, mental stress, physical activity, and addictive substances such as tobacco, nicotine, and alcohol. Epigenetics has an indispensable role in explaining the cause of developmental anomalies, genetic defects, and cancer as well as substance addiction (tobacco, cigarette, and alcohol). Epigenetic modifications may be seen in oral precancers and cancers. ${ }^{24}$ Various inflammatory reactions and infected pulp affect epigenetic modification, causing changes in gene expression. Lod et al stated that oral health and inflammatory conditions are associated with epigenetic alterations. ${ }^{25}$ Brook et al proposed that geneticepigenetic interactions may result in dental anomalies. ${ }^{26}$

\section{Periodontitis}

Gomez et al stated that due to bacterial challenge, destruction of tooth occurs supporting tissues in the susceptible host. ${ }^{27}$ In periodontitis, periods of activity and inactivity occur. Disease activity is mediated by the cytokines. Various studies have been done regarding periodontal disease activity and DNA methylation status that adds indispensable information related to pathogenesis of periodontal disease. ${ }^{28}$ In patients with periodontal disease, various pro- and anti-inflammatory cytokines act on the inflamed periodontal tissues, such as interleukin (IL)-1 $\beta, 6,10,4,1-\alpha$, and tumor necrosis factor- $\alpha$ (TNF- $\alpha) .{ }^{29-31}$ Chronic inflammation leads to DNA methylation, silencing the suppressors of cytokine signaling and inducing the active expression of cytokine signaling. ${ }^{32}$ IL-6, interferon $\gamma$ (IFNY) are the key cytokines that are overexpressed in inflamed tissue and may lead to bone resorption and sometimes severe periodontitis..$^{27,33}$ It was found that the chronic inflammation promotes DNA methylation. In chronic inflammation, hypermethylation at promoter site occurs at

\section{DNA methylation}



Fig. 1 The methy group sticks to DNA groove and blocks the binding of transcription factors to DNA. 


\section{Histone modification}



\section{Transcription activation (Open)}

\section{Transcription inactivation (Closed)}

Fig. 2 Histone deacetylases remove the acetyl groups, causing the chromatin to become more condensed, and they repress gene transcription.

gene TNF- $\alpha$, E-cadherins, and COX-2 (cyclo-oxygenase-2), ${ }^{34,35}$ whereas hypomethylation occurs at IFN $\gamma .{ }^{36}$ IL-6 shows no altered DNA methylation. ${ }^{37}$ TNF- $\alpha$ and COX-2 show decreased expression, whereas IF-6 and IFNF show increased expression in patients with chronic periodontitis. ${ }^{34-37}$

\section{Dental Pulp Stem Cells}

Dental pulp stem cells (DPSCs) have a noteworthy future in endodontics, thus cellular regulators are identified which plays an important role in determining the treatment plan. ${ }^{38}$ Stem cells have a significant role in regeneration of damaged tissue. ${ }^{39}$ Pulp regeneration has gained popularity in recent times due to changing treatment concept. ${ }^{9}$ They are divided under two headings: embryonic stem cells (ESCs) and postnatal in origin (adult stem cells [ASCs]). ${ }^{40}$ ESCs occur in an epigenetic-state, which are capable of self-renewal or differentiate into any body cell type (pluripotent), whereas ASCs exhibit more tissue restricted lineage potential (multipotent).41,42 Dental-derived stem cells are osteoblast-like cells and are able to differentiate into osteo/odontoblasts under appropriate stimulation. ${ }^{43}$ These cells have a unique capacity of bone regeneration. Eroschen $\mathrm{ko}^{43}$ stated that various HDAC inhibitors namely $\mathrm{NaB}$ and VPA upregulated osteoblast-related gene expression of DPSCs. VPA is believed to enhance matrix mineralization by increasing OPN and BSP expression-an effect that correlated with inhibition of HDAC $2 .{ }^{44}$ TSA and HDAC inhibitor promote proliferation and differentiation of odontoblasts via an upregulation of phosphoSmad2/3, Smad4, and nuclear factor I-C in DPSCs. ${ }^{45}$ VPA and TSA promote osteogenic differentiation by increasing expression of DMP-1, BMP-2/-4, and Nestin. ${ }^{46}$ Therefore, epigenetic alterations play a pivotal roles in regulating the expression of core genes in dental pulp cells.

\section{Others}

Epigenetic mechanisms may lead to various dental anomalies of the teeth such as rootless teeth and capdepont teeth. ${ }^{47}$ During odontoblast differentiation in dental stem cells, it is believed that cleft palate, cleft lip, and related syndromes may be associated with epigenetic modification. ${ }^{9}$

Oral squamous cell carcinoma (OSCC) hypermethylation of p16 occurs in 50 to $73 \%$ of cases and p15 in $60 \%$ of cases. ${ }^{48-51}$ Kresty et al identified hypermethylation of p16 INK4a and p14ARF in $57.5 \%$ and $3.8 \%$ of cases of severe dysplasia, respectively. ${ }^{52}$ Takeshima et al noted hypermethylation of p16, p14, p15, and p53 occurs in $18 \%$ mild versus 55\% severe dysplasia, $77 \%$ mild versus $65 \%$ severe dysplasia, 50\% mild versus 65\% severe dysplasia, and $32 \%$ mild versus $40 \%$ severe dysplasia, respectively. ${ }^{53}$ Youssef et al investigated that in 53\% of oral leukoplakias, hypermethylation of RARB2 occurs, but the histology of these lesions was not well defined. ${ }^{54}$ Genes that are shown to be hypermethylated in OSCC are the following ${ }^{51-55}$ : CDH1 (cadherin 1 type 1, a gene on chromosome 16q22.1), MGMT (a gene on chromosome 10q26), DAPK1 (death-associated protein kinase-1) on chromosome 9q22, TSP on chromosome 9q22, RARB2 gene (retinoic acid receptor B2 gene on chromosome 3p24). Hypermethylation of p14ARK, p16 INK4a, p15, MGMT, DAPK, GSTP1, and RARB is seen in dysplasias and in histologically normal-appearing margins of OSCC resections. ${ }^{52}$

Hypermethylation is seen in high frequency at tumor margins, in OSCC, and in dysplasias. However, these studies have no association with the degree of dysplasia and cannot signify the origin of OSCC. In this scenario, there is insufficient evidence to determine whether hypermethylation can be used as a predictive biomarker for the progression of dysplastic lesions. ${ }^{56}$ 


\section{Future of Epigenetics in Dentistry}

The field of dentistry is constantly evolving and getting more advanced, and those trends show no sign of stopping. Now, a group of researchers believe that within 10 years, your dentist may start taking a detailed look at your genetic makeup before dental treatments are recommended. Epigenetics is often used to describe studying long-term changes in the potential of cells. Researchers believe that there is a feasibility to influence the genes behavior, expressions, and their response to different circumstances. Now there are numerous different elements to examine a person's oral health:

- Individual genomes; plays role in dental development, risk of oral diseases.

- Oral microbiota.

- Epigenetic profile of the patient.

Epigenetics is often used to describe studying long-term changes in the potential of cells. One of the best benefits to using epigenetics in the future could be to identify potential disease and issues long before they begin. Unfortunately, epigenetics is still a way off from being used in the field of dentistry, so for now you will need to continue on with your 6-month appointments. This could help create a plan to reduce their impact.

\section{Conclusion}

Epigenetics is proving to be a valuable and insightful arm of genomics research. While there are no practical applications in dentistry at present, epigenetics may have profound influences in the future and so all clinicians should be aware of its basic principles. Furthermore, in terms of dental development, it may be possible to intervene early on to prevent hypodontia and a range of dental anomalies. In the shorter time frame, however, epigenetics could be used as a reliable screening tool for a range of dental anomalies, including inherited enamel defects, as well as a means of assessing an individual's susceptibility to dental caries and periodontal disease.

\section{Exciting times lie ahead!}

\section{Conflict of Interest}

None declared.

\section{References}

1 Waddington $\mathrm{CH}$. The basic ideas of biology. In: Towards a Theoretical Biology. Vol. 1. Edinburgh, UK: Edinburgh University Press; 1986:1-32

2 Sturtevant AH, Beadle GW. An introduction to genetics 1939. Ann Entomol Soc Am 1940;33(1):55

3 Medawar P, Medawar J. Epigenetic Inheritance and Evolution: The Lamarckian Dimension. Vol. 91. New York, NY: Oxford University Press; 1983:179-184

4 Hall BK. Evolutionary Developmental Biology. 2nd ed. Springer Science; 1992

5 Russo M, Riggs AD, eds. Epigenetic Mechanisms of Gene regulation. Vol. 32. 1996

$6 \mathrm{Wu} \mathrm{Ct}$, Morris JR. Genes, genetics, and epigenetics: a correspondence. Science 2001;293(5532):1103-1105

7 Allis CD, Jenuwein T. The molecular hallmarks of epigenetic control. Nat Rev Genet 2016;17(8):487-500
8 Allis CD, Caparros M, Jenuwein T, Reinberg D. Epigenetics. 2nd ed. Cold Spring Harbor Laboratory Press; 2015

9 Seo JY, Park YJ, Yi YA, et al. Epigenetics: general characteristics and implications for oral health. Restor Dent Endod 2015;40(1):14-22

10 Tchurikov NA. Molecular mechanisms of epigenetics. Biochemistry (Mosc) 2005;70(4):406-423

11 Bayarsaihan D. Epigenetic mechanisms in inflammation. J Dent Res 2011;90(1):9-17

12 Robertson KD. DNA methylation and human disease. Nat Rev Genet 2005;6(8):597-610

13 Gopalakrishnan S, Van Emburgh BO, Robertson KD. DNA methylation in development and human disease. Mutat Res 2008;647(1-2):30-38, 30-38

14 Jin B, Yao B, Li JL, et al. DNMT1 and DNMT3B modulate distinct polycomb-mediated histone modifications in colon cancer. Cancer Res 2009;69(18):7412-7421

15 Jin B, Tao Q, Peng J, et al. DNA methyltransferase 3B (DNMT3B) mutations in ICF syndrome lead to altered epigenetic modifications and aberrant expression of genes regulating development, neurogenesis and immune function. Hum Mol Genet 2008;17(5):690-709

16 Hark AT, Schoenherr CJ, Katz DJ, Ingram RS, Levorse JM, Tilghman SM. CTCF mediates methylation-sensitive enhancer-blocking activity at the H19/Igf2 locus. Nature 2000;405(6785):486-489

17 Loenen WA. S-adenosylmethionine: jack of all trades and master of everything? Biochem Soc Trans 2006;34(Pt 2): 330-333

18 Cheung HH, Lee TL, Rennert OM, Chan WY. DNA methylation of cancer genome. Birth Defects Res C Embryo Today 2009;87(4):335-350

19 Jin B, Li Y, Robertson KD. DNA methylation: superior or subordinate in the epigenetic hierarchy? Genes Cancer 2011;2(6):607-617

20 Barros SP, Offenbacher S. Epigenetics: connecting environment and genotype to phenotype and disease. J Dent Res 2009;88(5):400-408

21 Kaikkonen MU, Lam MT, Glass CK. Non-coding RNAs as regulators of gene expression and epigenetics. Cardiovasc Res 2011;90(3):430-440

22 Katsnelson A. Epigenome effort makes its mark. Nature 2010;467:646

23 Williams SD, Hughes TE, Adler CJ, Brook AH, Townsend GC. Epigenetics: a new frontier in dentistry. Aust Dent J 2014;59(1, Suppl 1):23-33

24 Singh NN, Peer A, Nair S, Chaturvedi RK. Epigenetics: a possible answer to the undeciphered etiopathogenesis and behavior of oral lesions. J Oral Maxillofac Pathol 2016;20(1):122-128

25 Lod S, Johansson T, Abrahamsson KH, Larsson L. The influence of epigenetics in relation to oral health. Int J Dent Hyg 2014;12(1):48-54

26 Brook AH. Multilevel complex interactions between genetic, epigenetic and environmental factors in the aetiology of anomalies of dental development. Arch Oral Biol 2009;54(Suppl 1): S3-S17

27 Gomez RS, Dutra WO, Moreira PR. Epigenetics and periodontal disease: future perspectives. Inflamm Res 2009;58(10):625-629

28 Burt B; Research, Science and Therapy Committee of the American Academy of Periodontology. Epidemiology of periodontal disease. J Periodontol 2005;76:1406-1419

29 Kinane DF, Hart TC. Genes and gene polymorphisms associated with periodontal disease. Crit Rev Oral Biol Med 2003;14(6):430-449

30 Shapira L, Wilensky A, Kinane DF. Effect of genetic variability on the inflammatory response to periodontal infection. J Clin Periodontol 2005;32Suppl 6 :72-86 
31 Moreira PR, Lima PMA, Sathler KOB, et al. Interleukin-6 expression and gene polymorphism are associated with severity of periodontal disease in a sample of Brazilian individuals. Clin Exp Immunol 2007;148(1):119-126

32 Stenvinkel P, Karimi M, Johansson S, et al. Impact of inflammation on epigenetic DNA methylation-a novel risk factor for cardiovascular disease? J Intern Med 2007;261(5):488-499

33 Lindroth AM, Park YJ. Epigenetic biomarkers: a step forward for understanding periodontitis. J Periodontal Implant Sci 2013;43(3):111-120

34 Zhang S, Barros SP, Moretti AJ, et al. Epigenetic regulation of TNFA expression in periodontal disease. J Periodontol 2013;84(11):1606-1616

35 Zhang S, Barros SP, Niculescu MD, Moretti AJ, Preisser JS, Offenbacher S. Alteration of PTGS2 promoter methylation in chronic periodontitis. J Dent Res 2010;89(2):133-137

36 Zhang S, Crivello A, Offenbacher S, Moretti A, Paquette DW, Barros SP. Interferon-gamma promoter hypomethylation and increased expression in chronic periodontitis. J Clin Periodontol 2010;37(11):953-961

37 Stefani FA, Viana MB, Dupim AC, et al. Expression, polymorphism and methylation pattern of interleukin- 6 in periodontal tissues. Immunobiology 2013;218(7):1012-1017

38 Duncan HF, Smith AJ, Fleming GJP, Cooper PR. Epigenetic modulation of dental pulp stem cells: implications for regenerative endodontics. Int Endod J 2016;49(5):431-446

39 Dupont KM, Sharma K, Stevens HY, Boerckel JD, Garcia AJ, Guldberg RE. Human stem cell delivery for treatment of large segmental bone defects. Proceedings of the National Academy of Sciences of the USA. 2010;107:3305-3310

40 Shukla V, Vaissière T, Herceg Z. Histone acetylation and chromatin signature in stem cell identity and cancer. Mutat Res 2008;637(1-2):1-15

41 Gronthos S, Mankani M, Brahim J, Robey PG, Shi S. Postnatal human dental pulp stem cells (DPSCs) in vitro and in vivo. Proc Natl Acad Sci U S A 2000;97(25):13625-13630

42 Ware CB, Wang L, Mecham BH, et al. Histone deacetylase inhibition elicits an evolutionarily conserved self-renewal program in embryonic stem cells. Cell Stem Cell 2009;4(4):359-369

43 Eroschenko VP. Bone. In: DiFiore's Atlas of Histology with Functional Correlations. Wolters Kluwer Health/Lippincott Williams \& Wilkins; 2008:79-98

44 Rodriguez-Lozano FJ, Insausti CL, Iniesta F, et al. Mesenchymal dental stem cells in regenerative dentistry. Med Oral Patol Oral Cir Bucal 2002;17(6):1062-1064
45 Jin H, Park JY, Choi H, Choung PH. HDAC inhibitor trichostatin A promotes proliferation and odontoblast differentiation of human dental pulp stem cells. Tissue Eng Part A 2013; 19(5-6):613-624

46 Duncan HF, Smith AJ, Fleming GJ, Cooper PR. Histone deacety-lase inhibitors epigenetically promote reparative events in primary dental pulp cells. Exp Cell Res 2013; 319(10):1534-1543

47 Sun $\mathrm{Q}$, Liu $\mathrm{H}$, Chen $\mathrm{Z}$. The fine tuning role of microRNARNA interaction in odontoblast differentiation and disease. Oral Dis 2015;21(2):142-148

48 Wong TS, Man MW, Lam AK, Wei WI, Kwong YL, Yuen AP. The study of p16 and p15 gene methylation in head and neck squamous cell carcinoma and their quantitative evaluation in plasma by real-time PCR. Eur J Cancer 2003;39(13):1881-1887

49 Goldenberg D, Harden S, Masayesva BG, et al. Intraoperative molecular margin analysis in head and neck cancer. Arch Otolaryngol Head Neck Surg 2004;130(1):39-44

50 Kulkarni V, Saranath D. Concurrent hypermethylation of multiple regulatory genes in chewing tobacco associated oral squamous cell carcinomas and adjacent normal tissues. Oral Oncol 2004;40(2):145-153

51 Kato K, Hara A, Kuno T, et al. Aberrant promoter hypermethylation of p16 and MGMT genes in oral squamous cell carcinomas and the surrounding normal mucosa. J Cancer Res Clin Oncol 2006;132(11):735-743

52 Kresty LA, Mallery SR, Knobloch TJ, et al. Alterations of $\mathrm{p} 16$ (INK4a) and p14(ARF) in patients with severe oral epithelial dysplasia. Cancer Res 2002;62(18):5295-5300

53 Takeshima M, Saitoh M, Kusano K, et al. High frequency of hypermethylation of p14, p15 and p16 in oral pre-cancerous lesions associated with betel-quid chewing in Sri Lanka. J Oral Pathol Med 2008;37(8):475-479

54 Youssef EM, Lotan D, Issa JP, et al. Hypermethylation of the retinoic acid receptor-beta(2) gene in head and neck carcinogenesis. Clin Cancer Res 2004;10(5):1733-1742

55 Ha PK, Califano JA. Promoter methylation and inactivation of tumour-suppressor genes in oral squamous-cell carcinoma. Lancet Oncol 2006;7(1):77-82

56 Tilakaratne WM, Nissanka-Jayasuriya EH. Value of HIF- $1 \alpha$ as an independent prognostic indicator in oral squamous cell carcinoma. Expert Rev Mol Diagn 2011;11(2):145-147 